\title{
Do Tournaments Have Incentive Effects?
}

\section{Ronald G. Ehrenberg}

Cornell University and National Bureau of Economic Research

\section{Michael L. Bognanno}

Temple University

\begin{abstract}
Much attention has been devoted to studying models of tournaments or situations in which an individual's payment depends only on his or her output or rank relative to that of other competitors. Academic interest derives from the fact that under certain sets of assumptions, tournaments have desirable normative properties because of the incentive structures they provide. Our paper uses nonexperimental data to test whether tournaments actually elicit effort responses. We focus on professional golf tournaments because information on the incentive structure (prize distribution) and measures of individual output (players' scores) are both available. We find strong support for the proposition that the level and structure of prizes in PGA tournaments influence players' performance.
\end{abstract}

\section{Introduction}

In recent years economists have devoted considerable attention to the normative properties of alternative compensation arrangements.

We have discussed our work in workshops at Cornell, Columbia, North Carolina (Greensboro), Massachusetts Institute of Technology, Arizona, Minnesota, the National Bureau of Economic Research, North Carolina State, Oberlin, Chicago, Pittsburgh, Brigham Young, Virginia, Northwestern, Amherst, Kentucky, Georgia State, and Brandeis, and we are grateful to numerous colleagues at these institutions and to a referee for their comments. This paper is based on work supported by the National Science Foundation under grant SES-8719592. The data set used in this paper will be archived at the Inter-University Consortium for Political and Social Research (P.O. Box 1248, Ann Arbor, Mich.) after January 1, 1991. 
Among the arrangements discussed have been tournaments, or situations in which an individual's payment depends only on his or her output or rank relative to that of other competitors (see, e.g., Lazear and Rosen 1981; Carmichael 1983; Green and Stokey 1983; Nalebuff and Stiglitz 1983; Malcomson 1984; O'Keefe, Viscusi, and Zeckhauser 1986; Rosen 1986). Tournament models are of more than academic interest since they may well describe the compensation structures applicable to many corporate executives, to professors (who can be thought of as being involved in promotion tournaments), to salespeople (whose bonuses often depend on their relative outputs), and to the more obvious example of professional sports tournaments. Academic interest derives from the fact that, under certain sets of assumptions, tournaments have desirable normative properties because of the incentive structures they provide.

Very few attempts have been made to test whether tournaments actually elicit desired effort responses. One experimental study of rank-order tournaments that used 225 paid undergraduate student volunteers as subjects did find mixed support for the theory, although disadvantaged (high-cost-of-effort) subjects provided more effort than the theory predicted (see Bull, Schotter, and Weigelt 1987). The lack of nonexperimental studies of tournaments is probably due to the difficulty of measuring both individuals' effort levels and the incentive structures competitors face in many circumstances.

To test in a nonexperimental setting whether tournaments do have incentive effects, we focus on golf tournaments because information on the incentive structure (prize distribution) and measures of individual output (players' scores) are both available. Under suitable assumptions, players' scores can be related to their effort and implications for scores drawn. In addition, data are available to control for factors other than the incentive structure that should affect output; these factors include player quality, quality of the rest of the field, difficulty of the course, and weather conditions. Implications can be drawn for both how well a player will perform during an entire tournament and how well he will perform on the last (fourth) round contingent, other things equal, on the marginal return to effort he faces in the tournament after the third round. Our empirical analyses make use of data from the 1984 men's Professional Golf Association (PGA) tour. ${ }^{1}$

\footnotetext{
${ }^{1}$ A short nontechnical companion paper (Ehrenberg and Bognanno 1990) replicates a portion of the empirical analyses presented here using data from the 1987 men's European PGA tour.
} 


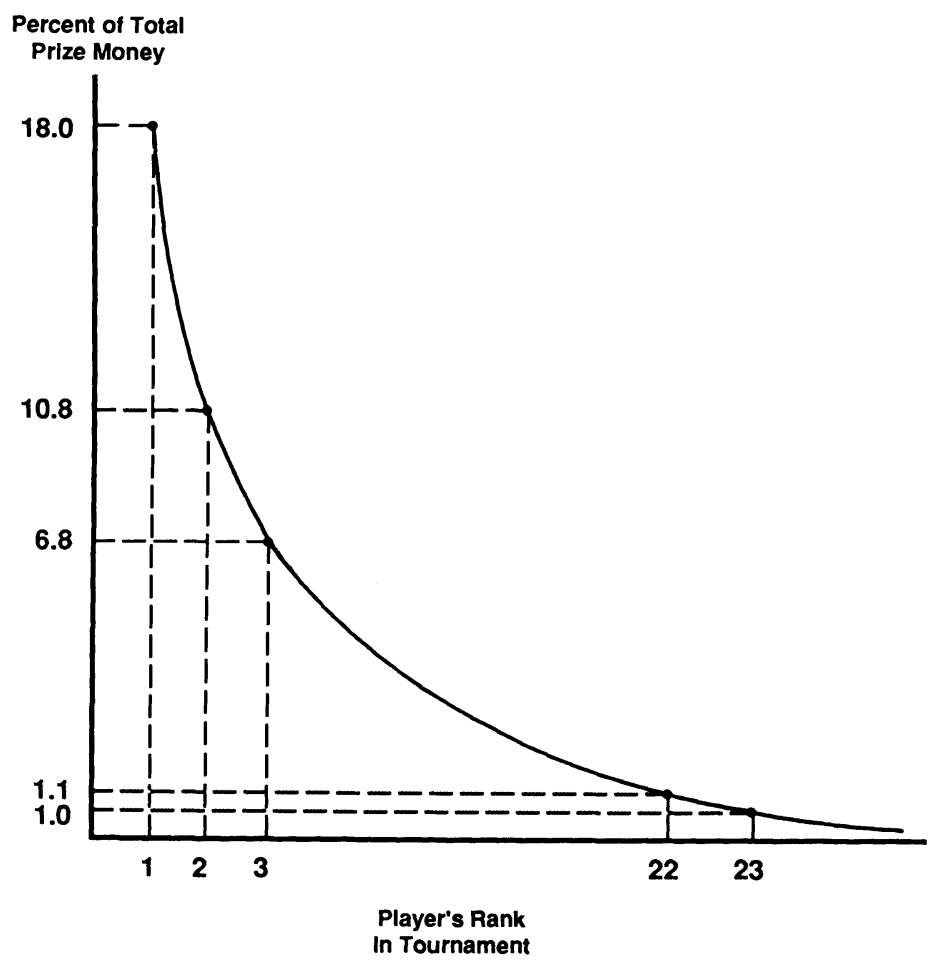

Fic. 1.-Share of total prize money going to players of different ranks: 1984 men's PGA tournament in the sample.

\section{The 1984 Men's PGA Tour: Institutional Characteristics and Hypotheses to Be Tested}

The typical golf tournament is composed of four rounds. Half the field is "cut" at the end of the second round, two additional rounds are played, and then prizes are awarded on the basis of the players' ranks after the final round. Of the 45 tournaments on the 1984 men's PGA tour, 40 were of this type, and data from them are used in our analyses.

Across these tournaments the structure of prize money by rank was virtually identical, although the level of prize money varied across tournaments. ${ }^{2}$ Figure 1 summarizes this structure. A key element of

${ }^{2}$ See Official 1985 PGA Tour Media Guide (1984). Of the 39 tournaments actually used in the study (the British Open was excluded for reasons that will be made clear shortly), 9 offered total prize levels between $\$ 200,000$ and $\$ 350,000,16$ had a total prize level of $\$ 400,000,8 \mathrm{had}$ a total prize level of $\$ 500,000$, and 6 offered total prize money in the $\$ 565,000-\$ 800,000$ range. 
the prize structure is that the marginal return from improving one's performance by one rank (or by not seeing one's performance decline by one rank) was much higher for people who were close to the leaders after three rounds than it was for people who were far from the leaders. For example, the marginal prize received from finishing second instead of third was 4.0 percent of the total tournament prize money, while the marginal prize received from finishing twentysecond instead of twenty-third was 0.1 percent of the total tournament prize money.

This structure of prizes, coupled with variations in the level of prizes across tournaments, suggests two types of tests of the hypothesis that tournament-type prize structures have incentive effects. First, since the structure of prizes is constant across tournaments, the prize differential for "winning" depends only on the level of total prize money. Thus one can focus on a tournament as a whole and ask, other things equal, whether higher total prize money leads to lower scores. Second, one can focus only on the last round of a tournament and ask, other things equal, whether a player's performance on the last round depends on the marginal return to effort he faces. The marginal return to effort will depend in turn on the total prize money in the tournament, the player's rank after the third round, and how many players are tightly bunched around him after three rounds. Both types of analyses are reported in the next section.

Before turning to the empirical results, however, we must discuss one institutional complication. Not every pro golfer who wanted to enter any given PGA tournament in 1984 could. Rather, a system of exemptions and priorities existed. At the risk of simplifying a very complex system, the system worked as follows (see 1984 Player's Handbook): (i) Any golfer who had won a major tournament since 1975 or any PGA tour tournament in 1983 could enter any tournament he wanted in both 1984 and 1985. (ii) Any golfer who failed to qualify under category $i$ and had won a major tournament in 1975 or any PGA tour tournament in 1982 could enter any tournament he wanted in 1984 but had no promise of entry for tournaments in 1985. (iii) If not all positions in a 1984 tournament were filled by individuals from categories i and ii, any golfer who finished among the top 125 money winners on the 1983 PGA tour could enter the tournament. (iv) Any remaining vacancies in a tournament were filled using other criteria (e.g., the sponsor-chosen players, lower-ranked players on the 1983 tour, or leaders from the PGA tour qualifying tournament).

As we shall show, this system of exemptions and priorities helps to explain which players entered which 1984 PGA tour tournaments; this is important because analyses that use data on the scores of entrants to tournaments will be subject to potential selectivity biases. In 
addition, individuals in categories ii, iii, and iv had to be very concerned about their total tour earnings in 1984. For unless they won a PGA tour tournament during the year, they had to finish in the top 125 money winners during the year in order to be assured of virtual automatic entry, if they desired, to PGA tour tournaments in 1985 (i.e., to be in category iii in 1985). In contrast, no matter what individuals in category $\mathrm{i}$ accomplished during the 1984 tour, they were assured the option of entry into any PGA tour tournament that they wanted to enter in 1985 .

Suppose that the latter group, whom we refer to henceforth as the exempt players, exhibited effort levels that were sensitive to the level and structure of prizes in a tournament. Because the former group, whom we henceforth refer to as the nonexempt players, had to worry about qualifying for the next year's tour, the level and structure of prize money in a tournament may not be an accurate indicator of their marginal financial return to effort. Rather, one would need to know also how an increase in effort for one of them increased the probability that he would be classified as an exempt player in 1985 and what the expected increase in the present value of his future earnings would be if he was so classified. As such, even if the exempt and nonexempt players' marginal responses to financial returns were equal, one might intuitively "expect" nonexempt players' effort levels, and hence scores, to be less sensitive to tournament-specific prize variables. An appendix (available from the authors) presents a simple omitted-variables model that indicates the precise (and restrictive) conditions under which this expectation is theoretically correct, and in the next section, we test to see whether responses differ between the two groups.

\section{Empirical Analyses}

Our empirical analyses proceed in stages. First, we estimate finalscore equations for players on the 1984 men's PGA tour. Next, we estimate the score after the second-round equations. Finally, we estimate final-round score equations.

\section{A. Final-Score Equations}

Our empirical work is based on two-contestant tournament models with heterogeneous competitors. Assuming that an individual's score is linearly related to his effort/concentration level, a tournamentspecific effect (due to course difficulty and weather conditions), and random factors and that effort/concentration has positive and increasing marginal cost, one can show that a player's final score in a 
tournament will depend on the prize differential for winning, measures of his and his opponent's ability, and tournament-specific factors. $^{3}$

Data are available in the 1985 Golf Digest Almanac (1984) and the Official 1985 PGA Tour Media Guide (1984) for each 1984 men's PGA tournament on the score by round, final rank, and prize money won for all players who entered and made the cut in each tournament. Data on each player's scoring average on all rounds during the year, a measure of his "ability," are available only for the top 160 money winners during the year; consequently, the analyses reported below are restricted to these individuals. Equations were estimated (with the data pooled across individuals and tournaments) in the form

$$
s_{j i}=a_{0}+a_{1} \text { TPRIZE }_{i}+a_{2} \mathbf{x}_{\imath}+a_{3} \mathbf{y}_{j}+a_{4} \mathbf{z}_{\imath}+v_{i j},
$$

where $s_{j i}$ is the final score of individual $j$ in tournament $i$, TPRIZE is the total prize money awarded in the tournament, $\mathbf{x}_{i}$ is a vector of variables to control for the difficulty of the tournament course and weather conditions, $\mathbf{y}_{j}$ is a vector of proxies for player $j$ 's ability, $\mathbf{z}_{i}$ is a vector of variables to control for the quality of other players in the field, and $v_{i j}$ is a random error term. If the theory of tournaments is correct, higher prizes should lead to lower scores; hence estimates of $a_{1}$ should be negative.

The controls for other tournament-specific factors are PAR, the par for the tournament course; DIST, the total course yardage; RATING, the PGA's evaluation of the playing difficulty of the course as it was set up for the tournament (expressed in strokes); and WAVE, the average of three raters' perceptions of the number of days during the tournament in which the weather significantly influenced player performance. A player's ability is proxied by SCOREAVE, his scoring average on all rounds played during the 1984 tour, and FCUT, the fraction of tournaments he entered in which he made the cut during the 1984 tour. Finally, quality of the other players in the field is proxied by FRACT, the fraction of all players in the tournament who made the cut that were ranked in the top 160 of total prize winners during the 1984 tour, and MPERAVE, a measure of the mean "performance average" on the 1984 tour of players in the tournament who made the cut. ${ }^{4}$

\footnotetext{
${ }^{3}$ See Ehrenberg and Bognanno (1989) for details.

${ }^{4}$ A player's performance average is a measure of how well he placed in the tournaments he entered during the year, with high performance averages indicating better players. The factors PAR, DIST, SCOREAVE, FCUT, FRACT, and MPERAVE were obtained from the 1985 Golf Digest Almanac. One-paragraph descriptions of the weather conditions that players faced each day of each tournament were obtained from the Official 1985 PGA Tour Media Guide; an average of three raters' perceptions of whether the weather each day adversely affected player performance (WAVE) was
} 
Estimates are reported in table 1. Separate analyses are presented for the entire sample, for the exempt players, and for the nonexempt players. ${ }^{5}$ A dummy variable for whether a tournament is a "major" tournament (i.e., the U.S. Open, the PGA, or the Masters) is also included. ${ }^{6}$ Winning a.major tournament typically provides substantial opportunities for lucrative endorsements; hence the total prize money variable understates the return to winning these tournaments.

As seen in the table, more difficult courses, as measured by PAR, DIST, and RATING, are seen to lead to higher scores. Similarly, each day of "bad" weather appears to raise players' scores by over two strokes. As expected, poorer players, as measured by SCOREAVE, play worse. Where significant, competing against a better field, as measured by FRACT and MPERAVE, appears to lead to higher scores.

Most striking, the coefficient of TPRIZE is negative as anticipated. The variable TPRIZE is measured in thousands of dollars; hence increasing the total prize money by $\$ 100,000$ is associated with each player's, on average, scoring 1.1 strokes lower during a tournament (col. 1). The results of estimating an equation in which TPRIZE is interacted with exempt status (col. 2) and of estimating separate equations for exempt (col. 3) and nonexempt (col. 4) players suggest that the coefficient of TPRIZE is slightly larger (in absolute value) for exempt players. As noted in the previous section, this may reflect either that exempt players' effort levels are more responsive to financial variables or that the nonexempt players' TPRIZE coefficient is biased toward zero because their marginal return to effort is also based both on how doing well in a tournament increases their probability of being classified as exempt in the next year and on what their expected increase in the present value of future income would be if so classified. Finally, other things equal, scores are lower in major tournaments but significantly so only for exempt players (col. 3). Since these players are the ones with the greatest chance of winning and thus gaining the endorsement value, this result seems sensible.

Several extensions warrant brief mention here. First, the results in table 1 may be subject to selection bias because the sample is restricted to the subset of players who entered and made the cut in each tourna-

then constructed. Finally, RATING was obtained for a majority of the courses from Jay Matolla of the Metropolitan Golf Association and for the other courses through telephone calls to state golf associations.

${ }^{5}$ When a nonexempt player won a tournament, his status was changed to exempt for subsequent tournaments in the year.

${ }^{6}$ The British Open, the fourth major golf tournament, was excluded from the analyses both because RATING was not available for it and because relatively few of the top U.S. players enter it. As a result, our sample actually includes 39 tournaments. 
TABLE 1

Final-Score Equations for the 1984 Men's PGa Tour: Data Pooled across Tournaments and Players

\begin{tabular}{|c|c|c|c|c|c|c|c|c|}
\hline \multirow[b]{3}{*}{ Constant } & \multicolumn{4}{|c|}{ ENTIRE SAMPLE } & \multirow{2}{*}{\multicolumn{2}{|c|}{$\begin{array}{c}\text { EXEMPT Players } \\
\text { (3) }\end{array}$}} & \multirow{2}{*}{\multicolumn{2}{|c|}{$\begin{array}{c}\text { NONEXEMPT } \\
\text { PlaYERS } \\
(4)\end{array}$}} \\
\hline & \multicolumn{2}{|l|}{ (1) } & \multicolumn{2}{|l|}{ (2) } & & & & \\
\hline & -324.099 & $(13.1)$ & -312.030 & (12.6) & -334.619 & (9.4) & -281.102 & (8.1) \\
\hline TPRIZE & -.011 & (6.9) & -.010 & $(6.1)$ & -.011 & (4.9) & -.010 & (3.9) \\
\hline TPRIZE $\times$ EXMT & & & -.002 & $(4.4)$ & & & & \\
\hline PAR & 1.495 & $(8.5)$ & 1.470 & (8.4) & 1.637 & (6.5) & 1.152 & (4.7) \\
\hline DIST & .006 & (7.4) & .006 & $(7.7)$ & .004 & (3.5) & .009 & (7.8) \\
\hline RATING & .211 & $(20.5)$ & .210 & $(20.5)$ & .233 & (15.0) & .185 & (13.4) \\
\hline WAVE & 2.394 & (13.3) & 2.360 & $(13.1)$ & 2.524 & $(8.7)$ & 2.155 & $(9.3)$ \\
\hline MAJ & -.698 & $(1.3)$ & -.654 & $(1.2)$ & -1.103 & (1.7) & -.811 & $(.9)$ \\
\hline SCOREAVE & 4.059 & $(14.0)$ & 3.906 & (13.5) & 3.948 & (9.6) & 3.831 & (9.4) \\
\hline FCUT & 4.346 & $(3.0)$ & 4.651 & $(3.3)$ & 4.026 & (1.9) & 5.114 & (2.6) \\
\hline FRACT & 4.277 & $(2.1)$ & 3.515 & (1.7) & 9.622 & (3.2) & -4.064 & (1.3) \\
\hline MPERAVE & .042 & $(10.6)$ & .045 & $(11.1)$ & .039 & $(7.5)$ & .055 & (8.5) \\
\hline $\bar{R}^{2}$ & .421 & & .426 & & .436 & & .410 & \\
\hline $\begin{array}{l}\text { Number of } \\
\text { observations }\end{array}$ & 2,432 & & 2,432 & & 1,03 & & 1,40 & \\
\hline
\end{tabular}

NoTE.-Absolute values of $t$-statistics are in parentheses. TPRIZE is total tournament money (in thousands); EXMT equals one if the player automatically qualifies to enter tournaments on the 1985 men's PGA; equals zero if he does not automatically qualify; PAR is par for the tournament course; DIST is the course yardage; RATING is the course rating: PGA evaluation of the playing difficulty of the course as it was set up for the tournament (expressed in strokes); WAVE is the average of three raters' perceptions of the number of days the weather significantly influenced player performance during the tournament; MAJ equals one if the tournament is the U.S Open, PGA, or Masters; equals zero otherwise; SCOREAVE is the player's scoring average on all rounds played performance do were ranked in the top 160 in total prize money won during the 1984 tour; MPERAVE is the mean performance average on the 1984 tour of players in the tournament who made the cut. A player's performance average is a measure of how high he placed in the tournaments he entered, with high performance averages indicatıng better performance (see the text for details). 
ment. Because of this, the effect of the total prize variable on players' final scores may be confounded with its effect on their entering and making the cut in a tournament. To control for this possible problem, one must have data on the players who entered each tournament and failed to make the cut; fortunately the PGA was able to provide us this information, as well as data on these players' scores during the first two rounds of the tournament.

To model separately the decision to enter a tournament and the probability of making the cut and then to estimate a bivariate selection model is a difficult task. Instead, we approximated this process and estimated a univariate probit equation of the probability of entering and making the cut. Following the approach initially suggested by Heckman (1979), we then used estimates from this equation to compute an estimate of the inverse Mills ratio for each individual, which was entered as an additional explanatory variable in equation (1) to control for selectivity bias. However, when this augmented final-score equation was reestimated, the coefficient of the additional variable never proved significant; nor did the TPRIZE coefficients differ from those reported in table 1 . Thus the estimates in table 1 do not appear to be subject to selection bias.

Second, the precision of the estimates presented in table 1 may be overstated because by implicitly assuming that the random error term is independent and identically distributed, we have not allowed for tournament-specific disturbances that are uncorrelated with the explanatory variables. One way to take account of this problem is to pool data within tournaments and to reestimate (1) using 39 observations on within-tournament averages as the units of observation. When this was done, the magnitude of the TPRIZE coefficient remained the same; however, its $t$-statistic fell to approximately 1.9. Alternatively, one can estimate a random effects model that allows for disturbances that have a component that is drawn randomly for each tournament from a distribution with zero mean but that is the same for each player in each tournament. When this was done, the TPRIZE coefficient was no longer statistically significant for nonexempt players; however, the coefficient continued to have the correct sign and remained statistically significant for exempt players.

\section{B. Score after Second-Round Equations}

Given the availability of data on the score after two rounds for all individuals who enter each tournament, we can estimate how the level of prize money influences players' performance in the early rounds of a tournament. Table 2 presents estimates similar to those found in table 1, except that the sample is now all entrants in each tournament 
TABLE 2

Score after Second-Round Equations for the 1984 Men's PGA Tour: Data Pooled across Tournaments and Players

\begin{tabular}{|c|c|c|c|c|c|c|c|c|}
\hline \multirow[b]{3}{*}{ Constant } & \multicolumn{4}{|c|}{ ENTIRE SAMPLE } & \multirow{2}{*}{\multicolumn{2}{|c|}{$\begin{array}{c}\text { EXEMPT PlayeRS } \\
(3) \\
\end{array}$}} & \multirow{2}{*}{\multicolumn{2}{|c|}{$\begin{array}{c}\text { NONEXEMPT } \\
\text { PLAYERS } \\
(4)\end{array}$}} \\
\hline & \multicolumn{2}{|c|}{ (1) } & \multicolumn{2}{|c|}{ (2) } & & & & \\
\hline & -128.429 & (7.0) & -121.57 & (6.6) & -148.561 & (5.6) & -93.279 & (3.6) \\
\hline TPRIZE & -.001 & $(.8)$ & -.000 & $(.2)$ & -.001 & $(.6)$ & -.000 & $(.0)$ \\
\hline TPRIZE $\times \mathrm{EXMT}$ & & & -.001 & (3.4) & & & & \\
\hline PAR & .558 & (4.4) & .556 & (4.4) & .759 & $(4.0)$ & .359 & $(2.1)$ \\
\hline DIST & .000 & $(.2)$ & .000 & $(.3)$ & -.000 & $(.8)$ & .001 & (1.6) \\
\hline RATING & .112 & $(16.2)$ & .111 & $(16.1)$ & .110 & (10.3) & .110 & $(12.0)$ \\
\hline WAVE2 & 2.148 & (14.7) & 2.12 & (14.7) & 2.106 & $(9.2)$ & 2.068 & (10.5) \\
\hline MAJ & .430 & (1.2) & .462 & (1.3) & .857 & (1.9) & -.673 & $(1.0)$ \\
\hline SCORE 12 & 1.913 & $(9.0)$ & 1.820 & (8.5) & 2.083 & (6.9) & 1.561 & $(5.1)$ \\
\hline FCUT & -1.855 & (1.7) & -1.825 & (1.6) & -1.001 & $(.6)$ & -2.751 & (1.7) \\
\hline FRACT2 & 11.683 & (6.3) & 11.088 & (5.9) & 10.383 & (3.8) & 8.543 & (2.8) \\
\hline MPERAVE2 & .008 & (3.0) & $.00 \varsigma$ & (3.5) & .008 & (2.5) & .017 & (3.2) \\
\hline $\bar{R}^{2}$ & .286 & & .288 & & .292 & & .270 & \\
\hline $\begin{array}{l}\text { Number of } \\
\text { observations }\end{array}$ & 3,44 & & 3,4 & & 1,378 & & $2,0^{\prime}$ & \\
\hline
\end{tabular}

Note.-Absolute values of $t$-statistics are in parentheses. All variables are defined as in table 1, except for WAVE2, which now refers to the weather during the first two rounds of the tournament: SCORE12, which now refers to the player's scoring average on all first and second rounds he played on the 1984 tour; and FRACT2 and MPERAVE2, which now refer to all entrants in the tournament. 
(among the top 160 money winners in the year) and the outcome variable is now the player's score after the second round, prior to the cut's being made. In addition, the weather variable now refers to the weather on the first two days of the tournament and the field quality variables to all entrants in each tournament rather than to those who made the cut.

The most striking finding is that the total tournament prize money does not appear to influence players' performance during the first two rounds. Only for exempt players in the specification in which exempt status is interacted with the prize variable (col. 2) is there any evidence of an effect, and even for this group, an increase in prize money of $\$ 100,000$ would be associated with scores that were only 0.1 strokes lower per player after the first two rounds. This finding is consistent with the hypothesis that a player's difficulty in maintaining concentration occurs primarily in the later rounds of a tournament when fatigue is more likely to have set in. ${ }^{7}$

Of course, the possibility still exists that the results in table 2 are subject to selection bias because they are based on a sample of tournament entrants; we may be confounding the effect of a tournament's prize level on the probability that players enter the tournament with its effect on their scores. To check for this, Heckman's (1979) two-step procedure was once again employed. First, several probit equations of the probability of entering a tournament were estimated in which entry probabilities were specified to be a function of a player's exempt status, his total career earnings prior to 1984 , his age, the chronological order of a tournament during the year, the status of the tournament as a major tournament, the tournament's total prize money, and the player's scoring average on all rounds in which he played during the 1984 tour or on all first and second rounds in which he played during the tour. Separate sets of coefficients were estimated for exempt and nonexempt players. ${ }^{8}$

These estimates were used to obtain estimates of the inverse Mills ratio for each individual entered in each tournament, and augmented versions of the score after the second-round equations were then

\footnotetext{
${ }^{7}$ Generalizations of tournament theory to the $n$-person case suggest that the marginal response of effort to the prize spread declines as the number of competitors gets larger (see McLaughlin 1988). Since roughly twice as many players compete in the first two rounds of a tournament as in the last two, this provides another explanation for why one might observe scores for the tournament as a whole that are more sensitive to tournament prize levels than scores for the first two rounds.

8 These estimates are found in Ehrenberg and Bognanno (1989) and are consistent with hypotheses from tournament theory that individuals will "sort" themselves into tournaments. For example, exempt players were seen to be more likely, and nonexempt players less likely, to enter major tournaments and tournaments with higher prize money.
} 
estimated. However, again the coefficients of the estimated inverse Mills ratio never proved significant, and the estimated coefficients of the total prize variable were identical to those found in table 2 . Thus the conclusion that the level of prize money at best only marginally affects the level of effort during the first two rounds for exempt players and does not affect the level of effort during that time for nonexempt players appears to be valid.

\section{Final-Round Score Equations}

Consider a golfer playing in two tournaments with the same total prize money. Suppose that he scores a 72 on each of the first 3 days of both tournaments, but because of random factors that influence his opponents' performance, he finds himself in third place in the first tournament but in twentieth place in the second tournament. Given the structure of PGA tournament prizes (fig. 1), he faces a greater marginal return to effort/concentration in the first tournament, should exert more effort/concentration there, and, on average, should have a lower final-round score in that tournament.

Of course, a player's rank after three rounds and the total tournament prize money are only two of the elements that influence the marginal return to effort/concentration that he faces. One must also take into account how closely his competitors are "bunched" around him. As such, we defined six different variables to serve as proxies for the marginal return to effort an individual faces. These are all illustrated in figure 2.

In the figure, suppose that the curve $P P$ shows the relationship between a player's final rank in a tournament and the prize money he will be awarded. Consider an individual who after the third round is at rank $R$. If he remains at that rank, he will be awarded the amount $O A$ at the end of the tournament.

The first three marginal return variables we compute ignore how tightly bunched competitors are around the player and are based on the return to improving performance, or of having it get worse, by one rank. The variable DPRIZE3 is the actual marginal reduction in prize money if the individual's rank at the end of the tournament was one higher (worse) than his current rank; this is given by $A D$ in the figure. The variable UPRIZE3 is the actual increase in prize money the individual would gain if he improved his rank by one; this is given by $A C$. The variable MIDPRIZ3 assumes that the individual takes into account the cost of losing one rank, as well as the benefit from improving one rank. It is defined as the actual average absolute change in prize money if the rank at the end of the tournament is either one 


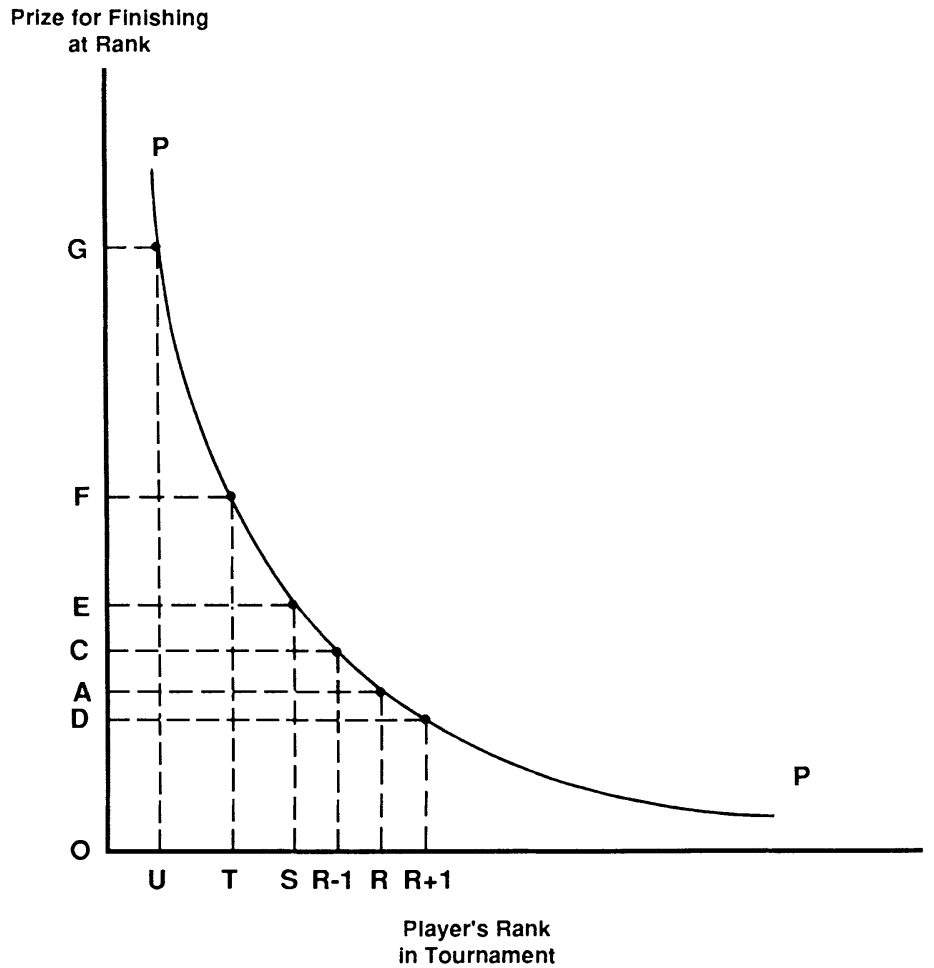

Fig. 2.-Alternative measures of marginal return to effort/concentration in a tournament.

lower or one higher than $R$, and it is given in the figure by the average of the lengths of $A C$ and $A D$.

Presumably, increased effort/concentration directly affects a player's score, not his rank. The effect of increased concentration on rank then depends on the number of competitors closely bunched around the player. The next three measures take this into account. They are the actual increase in prize money the individual would receive if he improved his scores relative to those of his competitors by one stroke (LES1PRIZ), two strokes (LES2PRIZ), or three strokes (LES3PRIZ). If improvements of one, two, and three strokes would cause the individual's rank to improve, respectively, to $S, T$, and $U$ in the figure, these variables' magnitudes in turn would be given by $A E, A F$, and $A G$.

Each of these six variables was computed for each individual in each tournament. Equations were then estimated, using data pooled across individuals and tournaments, in which a player's score in the 
final round of a tournament was specified to be a function of his scores on the first 3 days of the tournament, the adverse effect of weather, if any, on players' performance on the first 3 days and on the final day of the tournament, and a marginal return to effort variable. Given the weather, a player's scores on the first 3 days, which are probably the best predictors of how well he is currently playing, should be positively associated with his score on the final day. Given his scores on the first 3 days, the poorer the weather was on those days, the lower his score on the final day should be. However, the poorer the weather on the final day, other things equal, the higher his score on the final day should be.

A player's scores on the first 3 days of a tournament are not exogenous, but rather depend on the prize differential for winning, measures of his and his opponents' ability, and tournament-specific factors such as course difficulty and the weather on those days. Similarly, the estimated marginal return to effort a player faces is also not exogenous since it depends on his scores and his opponents' scores on the first 3 days, both of which depend in turn on the factors described above. As such, a player's scores on the first 3 days and the marginal return to effort he faces on the last day are treated as endogenous and the equations are estimated using an instrumental variable method.

Estimates of the coefficients of the marginal return to effort variables from these equations are reported in table 3 . The pattern of results is remarkably consistent across specifications. The marginal return to effort variables do affect players' scores in the final round, with larger marginal returns associated with lower scores. ${ }^{9}$ This result is observed, however, only for exempt players. The magnitudes of the relationship for each of the marginal return to effort variables (except for LES3PRIZ) are such that, other things equal, a player whose marginal return to effort was one standard deviation above the mean marginal return in the sample would score $1.0-1.7$ strokes lower in the final round of the tournament. ${ }^{10}$

One may argue that, in theory, a player's effort in the last round of a tournament also depends on his ability relative to that of the players who are closely bunched around him. To see how inclusion of such measures would influence the importance of financial variables, we

\footnotetext{
${ }^{9}$ Formal specification tests (see Hausman 1978) permit one to reject the hypothesis that the set of variables treated as endogenous should be treated as exogenous. This finding is important because if one erroneously treats them as exogenous, many of the coefficients of the marginal prize variables switch signs and become positive.

${ }^{10}$ See Ehrenberg and Bognanno (1989) for details. The estimated LES3PRIZ effect is less than one stroke. Improving one's performance by three strokes relative to that of one's competitors in a round is a difficult task, so this measure is probably less relevant than the others.
} 
TABLE 3

Coefficients of Marginal Return to Effort Variables in Final-Round-Score Equations for the 1984 Men's PGA Tour: Various SPEcifications

\begin{tabular}{lllc}
\hline \hline Specification & All & Exempt & Nonexempt \\
\hline DPRIZE3 & -.042 & -.042 & -.032 \\
UPRIZE3 & $(2.7)$ & $(1.8)$ & $(.9)$ \\
& -.236 & -.310 & -.070 \\
MIDPRIZ3 & $(3.5)$ & $(2.6)$ & $(.6)$ \\
LES3PRIZ & -.212 & -.278 & -.088 \\
& $(3.3)$ & $(2.5)$ & $(.8)$ \\
LES2PRIZ & -.049 & -.052 & .009 \\
LES1PRIZ & $(2.0)$ & $(1.3)$ & $(.3)$ \\
& -.088 & -.135 & .025 \\
& $(2.6)$ & $(2.4)$ & $.5)$ \\
& -.181 & -.306 & $(1.0)$ \\
\hline
\end{tabular}

NotE.-Absolute values of $t$-statistics are in parentheses. DPRIZE3 is the actual marginal reduction in prize money (in thousands) if rank at the end of the tournament is one higher (worse) than the individual's third-round rank; UPRIZE3 is the actual marginal increase in prize money (in thousands) if rank at the end of the tournament is one lower than the individual's third-round rank; MIDPRIZ3 is the actual average marginal absolute changes in prize money (in thousands) if rank at the end of the tournament is one lower or one higher than the individual's third-round rank; and LES3PRIZ is the actual marginal increase in prize money (in thousands) if the individual improved his rank after the third round by reducing his score by three strokes relative to the rest of the field $($ LES2PRIZ $=$ two strokes, LES1PRIZ = one stroke). All specifications also include SCORE1, SCORE2, SCORE3, WAVE123, and WAVE4 and use instruments used for SCORE1, SCORE2, SCORE3, and the marginal return to effort variables. The instruments were obtained using TPRIZE, MAJ, PAR, DIST, RATING, FRACT, MPERAVE, FCUT, SCOREAVE (which are all defined in table 1), and SCORE12, the player's scoring average on all first and second rounds he played on the 1984 tour; SCORE3A, the player's scoring average on all third rounds he played in the 1984 tour; WAVE1-WAVE3, average of three raters' perceptions of whether the weather significantly influenced player performance during the first, second, and third rounds, respectively, of the tournament; and PERAVE, the player's performance average on the 1984 PGA tour (see table 1).

computed for each player in each tournament the differences between his average score per round during the year and the average of the average scores per round during the year of all players within two and three strokes of him, in either direction, at the end of the third round of play in the tournament. These variables (one at a time) were added to the specifications that underlie table 3 , and these extended equations were reestimated for the exempt sample. Since the average ability of the players around a player after the third round is endogenous, instruments for these relative ability variables were also used.

It is quite striking that, although the magnitudes of the coefficients of the marginal prize variables declined slightly when the controls for competitor quality were included, one still observes larger marginal prizes being associated with lower final-round scores. ${ }^{11}$ Furthermore, all the marginal prize variables' coefficients, except one, remained statistically significantly different from zero.

\footnotetext{
${ }^{11}$ See Ehrenberg and Bognanno (1989) for results.
} 


\section{Concluding Remarks}

This paper has provided nonexperimental evidence that tournaments have incentive effects. Our analyses of data from the 1984 men's PGA tour suggest that the level and structure of prize money do influence players' performance. Higher prize levels do lead, other things equal, to lower scores, but this effect occurs primarily in the later rounds of a tournament when fatigue has set in and it is more difficult for players to maintain concentration. Given a player's performance in the first three rounds of a tournament, his performance in the last round also appears, other things equal, to depend on the marginal returns to effort he faces, with players who face larger marginal returns scoring lower. The level of prize money in tournaments also influences who enters the tournaments, with higher prize money attracting better (exempt) players.

The influence of tournament prizes on performance was observed primarily for exempt players. As described above, this may reflect either that exempt players are more responsive to the reward structure or that a tournament's prize level does not adequately reflect the reward structure that nonexempt players face, since these players must be concerned with how their finish in a tournament will influence their probability of qualifying for exempt status on next year's tour. Evidence we have obtained from analyses of data from the 1984 men's senior tour for golfers aged 50 and older, which are reported elsewhere, provides some support for the former hypotheses: that better players are, in fact, more responsive to financial incentives. ${ }^{12}$

Our work is only an initial empirical study of the incentive effects of tournaments, and there are a number of directions in which future research might proceed. First, replications and extensions using data from other sports in which absolute measures of output are available, the level and structure of prize money differ, and the form of tournaments differs would obviously be desirable. Professional bowling is particularly attractive in this regard because bowling tournaments have a match play element to them in their concluding stages. ${ }^{13}$ Analyses using data from more than one year would also be desirable; our within-year analyses focus on how players allocate effort/concentration within a year but show no evidence on how increasing prize levels over time influence who enters the profession and the resources they devote to conditioning and practice during the "offseason." 1989).

${ }^{12}$ These analyses are not reported here for brevity (see Ehrenberg and Bognanno

${ }^{13}$ Research using data from professional bowling is undertaken in Bognanno (1990). 
Second, all our analyses are derived from simple two-person models that yield implications for the output/scores of an individual player. Generalization to $n$-person tournaments would yield implications about the entire distribution of scores one might expect to observe, and empirical analyses of the distribution of final scores could then be undertaken.

Third, our analyses assumed that the tournament prize structure influences output/scores through its effect on effort/concentration levels. Players can also choose conservative (e.g., hit down the center of a fairway) or risky (e.g., try to cut across a dogleg) strategies, and depending on a player's ability relative to the rest of the field or his rank after each round, different strategies may be pursued. Models that also included the choice of strategies that differ in risk undoubtedly would yield additional empirical implications. ${ }^{14}$

Fourth, there are normative issues relating to the level and structure of prizes that we actually observe in tournaments. Can we infer from this structure what the objective functions of the PGA tour and tournament sponsors actually are? Can we estimate whether the marginal cost to sponsors of higher-prize tournaments is less than, equal to, or greater than the marginal benefits they receive? Can we infer whether golf tournaments' prizes are structured efficiently? To answer such questions will require one to go far beyond the scores of players in tournaments and to analyze more generally the operations of the PGA tour and its sponsors.

Finally, while analyses of sports tournaments are of interest in themselves, there is the broader question of the extent to which tournament theory can help to provide an explanation for the structure of compensation we observe among corporate executives. As is well known, situations in which opportunities exist for one executive to sabotage a rival's performance are not conducive to tournament-type pay structures (see Lazear 1989). Nevertheless, devising ways to empirically address this question should rank high on the research agenda of economists interested in compensation issues.

\section{References}

Bognanno, Michael L. "An Empirical Test of Tournament Theory.” Ph.D. dissertation, Cornell Univ., 1990.

Bronars, Stephen. "Risk Taking Behavior in Tournaments." Manuscript. Santa Barbara: Univ. California, February 1987.

$\rightarrow$ Bull, Clive; Schotter, Andrew; and Weigelt, Keith. "Tournaments and Piece Rates: An Experimental Study." J.P.E. 95 (February 1987): 1-33.

\footnotetext{
${ }^{14}$ See Bronars (1987) for an initial effort in this direction.
} 
$\rightarrow$ Carmichael, H. Lorne. "The Agent-Agents Problem: Payment by Relative Output." J. Labor Econ. 1 (January 1983): 50-65.

Ehrenberg, Ronald G., and Bognanno, Michael L. "Do Tournaments Have Incentive Effects?” Manuscript. Ithaca, N.Y.: Cornell Univ., June 1989.

$\rightarrow \rightarrow-$ "The Incentive Effects of Tournaments Revisited: Evidence from the European PGA Tour." Indus. and Labor Relations Rev. 43 (suppl.; February 1990): 74-S-88-S.

$\rightarrow$ Green, Jerry R., and Stokey, Nancy L. "A Comparison of Tournaments and Contracts.” J.P.E. 91 (June 1983): 349-64.

Hausman, Jerry A. "Specification Tests in Econometrics." Econometrica 46 (November 1978): 1251-71.

Heckman, James J. "Sample Bias as a Specification Error." Econometrica 47 (January 1979): 153-61.

$\rightarrow$ Lazear, Edward P. "Pay Equality and Industrial Politics." J.P.E. 97 (June 1989): 561-80.

$\rightarrow$ Lazear, Edward P., and Rosen, Sherwin. "Rank-Order Tournaments as Optimum Labor Contracts." J.P.E. 89 (October 1981): 841-64.

McLaughlin, Kenneth J. "Aspects of Tournament Models: A Survey." In Research in Labor Economics, vol. 9, edited by Ronald G. Ehrenberg. Greenwich, Conn.: JAI, 1988.

$\rightarrow$ Malcomson, James M. "Work Incentives, Hierarchy, and Internal Labor Markets." J.P.E. 92 (June 1984): 486-507.

$\rightarrow$ Nalebuff, Barry J., and Stiglitz, Joseph E. "Prizes and Incentives: Towards a General Theory of Compensation and Competition." Bell J. Econ. 14 (Spring 1983): 21-43.

1985 Golf Digest Almanac. New York: Simon and Schuster, 1985.

1984 Player's Handbook. Ponte Vedra, Fla.: PGA Tour, 1984.

Official 1985 PGA Tour Media Guide. Ponte Vedra, Fla.: PGA Tour, 1984.

O'Keefe, Mary; Viscusi, W. Kip; and Zeckhauser, Richard J. "Economic Contests: Comparative Reward Schemes.” J. Labor Econ. 2 (January 1984): $27-$ 56.

$\rightarrow$ Rosen, Sherwin. "Prizes and Incentives in Elimination Tournaments." A.E.R. 76 (September 1986): 701-15. 